\title{
A Universidade de Passo Fundo e o desenvolvimento regional ${ }^{1}$
}

\author{
Luciane Spanhol Bordignon ${ }^{2}$
}

\section{RESUMO}

A educação superior é descrita como locus da produção do conhecimento, principalmente nos Programas de Pós-graduação stricto sensu. Neste contexto, um dos desafios a serem enfrentados diz respeito ao desenvolvimento regional no cenário da educação superior. Este artigo tem como objetivo analisar o desenvolvimento regional associado a uma universidade comunitária, mais especificamente a Universidade de Passo Fundo (UPF). Para realizá-lo, utilizou-se de fontes bibliográficas e entrevistas com gestores institucionais. Os encaminhamentos conclusivos resgatam os avanços e desafios desse estudo, sinalizando as questões que envolvem a universidade e o desenvolvimento regional.

Palavras-chave: Educação Superior; Universidade Comunitária; Desenvolvimento Regional.

\section{Community college and regional development}

\begin{abstract}
The higher education is described as the locus of the knowledge production, mainly in Post-graduation programs stricto sensu. In this context, one of the challenges to be faced regards the regional development in the higher education scenario. This article aims to analyze the regional development associated with the community college, more specifically to UPF university (Universidade de Passo Fundo). In order to have it done, bibliographic resources and interviews with institutional managers were used. The conclusive directions bring back the advances and challenges of this study, point out the issues that involve the university and the regional development.
\end{abstract}

Key words: Higher Education. Community College. Regional Development.

\section{INTRODUÇÃO}

Na esteira das políticas internacionais e nacionais da educação superior, as instituições de ensino superior vivenciam a dicotomia entre o global e o local, no sentido de expandir suas ações e programas na internacionalização do conhecimento e na mobilidade docente e discente, ao mesmo tempo preocupando-se com as questões locais e a superação das problemáticas dos seus territórios.

\footnotetext{
${ }^{1}$ As reflexões, propostas e vivências deste estudo fizeram parte da pesquisa realizada para a feitura da tese $A$ Pós-graduação como Interlocutora das relações Universidade e Comunidade (BORDIGNON, 2014).

${ }^{2}$ Doutora em Educação. Professora na Faculdade de Educação (FAED) da Universidade de Passo Fundo (UPF). Integrante do Grupo de Estudos sobre Universidade - GEU/UPF e do Grupo de Pesquisa e Extensão em Políticas Gestão da Educação (GPEPGE), da FAED/UPF. E-mail: lucianebordignon@upf.br
} 
Entre as instituições de ensino superior, encontram-se as universidades comunitárias. Sua criação deve-se, também, ao espírito associativo, com forte presença nos estados do sul do país. Este artigo tem como objetivo analisar o desenvolvimento regional associado a uma universidade comunitária, mais especificamente a Universidade de Passo Fundo (UPF), situada no planalto médio do Rio Grande do Sul. Para realizá-lo, utilizou-se de fontes bibliográficas e entrevistas com gestores institucionais. No quadro desta investigação, foi possível capturar "as vozes" dos gestores institucionais - Vice-Reitor de Pesquisa e PósGraduação, Vice-Reitora de Extensão e Assuntos Comunitários, Coordenadores dos Programas de Pós-graduação stricto sensu3, no período de 2011 a 2013, acerca da Universidade Comunitária e do desenvolvimento regional.

$\mathrm{Na}$ perspectiva deste estudo, evidencia-se que o desenvolvimento regional faz parte do compromisso social da universidade e legitima seu caráter comunitário.

\section{ALGUMAS REFLEXÕES SOBRE A UNIVERSIDADE E AS UNIVERSIDADES COMUNITÁRIAS}

A etimologia da palavra universidade, segundo o dicionário Houaiss, vem do latim universitas, que significa 'universalidade, totalidade; companhia, corporação, colégio, associação. Conforme analisa Chauí (2001), a universidade é uma instituição social. Isto significa que ela realiza e exprime de modo determinado a sociedade de que é e faz parte. Não é nenhuma realidade separada e sim uma expressão historicamente determinada de uma sociedade determinada. A universidade é o lugar de produção de conhecimento, e isto se dá por meio da prática e do desenvolvimento da pesquisa. Como instituição eminentemente social, a Universidade deve ser comprometida com a difusão dos conhecimentos, seus avanços e com a ampliação da cidadania.

Vale destacar que a Universidade não é a única instituição que produz ciência, mas o faz por meio de procedimentos próprios. Segundo Franco et al "a universidade como instituição do conhecimento por excelência, cuja natureza é marcada pelo duplo papel de formação das novas gerações e produção do conhecimento é habitat propício para

\footnotetext{
${ }^{3}$ Os símbolos G1, G2, G3, G4, G5, G6, G7 e G8 indica os gestores institucionais (Vice-Reitor de Pesquisa e Pós-Graduação, Vice-Reitor de Extensão e Assuntos Comunitários, Coordenadores dos PPGs em Educação, Letras, História e em Envelhecimento Humano), no período de 2011 a 2013. Nas "vozes" dos entrevistados, para diferenciar o texto, será utilizada a fonte Lucinda Console.
} 
desencadear a força estratégica da produção da pesquisa científica" $(2009$, p. 92).

A Universidade, para Freire (2003), tem dois momentos que se relacionam permanentemente: um é o momento em que conhecemos o conhecimento existente; o outro em que produzimos o novo conhecimento. O desafio contemporâneo para a educação brasileira, segundo Severino (2012), continua sendo o compromisso com a formação cultural das pessoas, em todas suas dimensões existenciais, e que, no que lhe cabe essa formação pressupõe um necessário e permanente envolvimento com o processo de construção do conhecimento, com o processo de pesquisa.

A universidade é o espaço central e estruturante da vida social. A ascensão para níveis superiores de escolaridade, principalmente no ensino superior, constitui-se como novas expectativas e aspirações dos acadêmicos e das respectivas famílias, embora, no Brasil, muitos jovens ainda não têm acesso a este nível de ensino. Nóvoa afirma que "a função maior na Universidade é proporcionar às pessoas os instrumentos da cultura e do pensamento" (2011, p. 2). Assim, para que a Universidade possa cumprir com sua função social, "precisa sair de seus muros e buscar a sua inserção na sociedade mais ampla, analisando, discutindo e equacionando os diferentes problemas existentes, promovendo, assim, a contextualização da realidade" (ARAUJO, 1998, p. 178). Considera-se, então, que a conquista do saber não se dá exclusivamente por meio de fórmulas acadêmicas, mas, também e principalmente, no âmago das relações sociais. Araújo acrescenta "o saber é visto como produção coletiva dos homens que surge de sua atuação na vida real, por intermédio de suas relações com a natureza, com os outros e com ele próprio" (p. 179). Neves (2007) em seu texto Desafios da Educação Superior salienta que há uma demanda crescente por educação superior e um reconhecimento sobre sua importância estratégica para o desenvolvimento econômico e social. Igualmente implica em mudanças no perfil de formação, qualificando-a no tocante ao domínio de conhecimento, na capacidade de aplicá-los criativamente na solução de problemas concretos, no desenvolvimento de espírito de liderança e polivalência funcional, bem como, na maior adaptabilidade à mudança tecnológica, de informação e comunicação. Fundamental é que essas mudanças assegurem a ampliação do acesso à educação superior.

Como instituição social, a universidade, está imersa na tensão local/global. Em se tratando do âmbito da comunidade, Readings (2002), salienta que a universidade poderia funcionar como o lugar habitado por uma comunidade de pensadores, sob a condição de que repensemos criticamente a noção de comunidade, de maneira a libertá-la da tradição organicista e da corporação medieval. Neste sentido, comunidade é o local no qual a vida 
acontece, em uma rede de interações humanas. O estudo das comunidades deve caminhar junto com o estudo dos conflitos, das problemáticas socioculturais e econômicas das próprias comunidades.

No contexto da Universidade, com suas novas arquiteturas, categorias, modelos insere-se as Universidades Comunitárias.

As Universidades Comunitárias (UC) estão preconizadas na Constituição Federal de 1988 e na Lei de Diretrizes e Bases da Educação Nacional de 1996. (LDB). A Constituição Federal (1988) refere-se que poderão ser consideradas comunitárias, confessionais ou filantrópicas as escolas que provarem finalidade não lucrativa e aplicarem seus excedentes financeiros em educação. O artigo 20 da LDB (1996) aponta como comunitária as universidades que são constituídas por grupo de pessoas físicas ou por uma ou mais pessoas jurídicas, inclusive cooperativas de professores e alunos que incluam na sua entidade mantenedora membros da comunidade.

No Brasil, segundo Schmidt (2011), a terminologia comunitária também está marcada por uma profusa utilização, particularmente no âmbito da educação. Há pelos menos seis distintas referências históricas de educação comunitária no país: as escolas e universidades confessionais, desde a década de 1550; as escolas comunitárias de imigrantes, a partir dos anos 1820; a Campanha Nacional de Escolas da Comunidade, iniciada na década de 1930; o Desenvolvimento de Comunidade, desde a década de 1940; as escolas comunitárias (re)criadas por mobilização popular, a partir dos anos 1970; e as universidades comunitárias regionais, criadas pelas comunidades do Sul a partir dos anos 1940. O uso do termo comunitário, conforme Frantz (2004), se abre e se dilui, de certa forma, na definição de iniciativas que brotam no seio da sociedade civil. Porém, é importante observar que, malgrado essa abertura para usos e sentidos diversos, a noção do comum, quando se materializa em ações sociais, desperta identidade, mobiliza interações e pode levar à construção de compromissos e responsabilidades, pode fundar processos sociais. Assim, é um conceito que contém a ideia de ação, de agregação de sujeitos, de integração de interesses, de associação de forças, de viabilização de potencialidades.

Ao referir-se sobre as universidades comunitárias, Neves (1997) salienta que por suas características constituem-se em fenômeno novo e suas transformações indicam as tendências e os limites de ação não empresarial no campo da educação superior. (...). Estão a serviço do público em geral, atendem demandas de diferentes segmentos voltados ao interesse da região. A mantenedora é uma fundação considerada de utilidade pública, com fins filantrópicos, que 
não remunera seus quadros diretores. Há uma ampla participação de representantes da sociedade e do poder público local (segmentos como sindicatos, associações, prefeituras) na administração da entidade mantenedora.

A universidade comunitária, segundo Tramontini e Braga (1988), é uma instituição particular porque não se deu na esfera pública, nem o Estado é o seu principal mantenedor e apresenta, contudo, uma especial dimensão pública por causa das seguintes características: a instituição mantenedora não está subordinada a nenhum interesse empresarial de pessoas físicas ou grupos, mas unicamente a um objetivo social; seus bens não são propriedade de ninguém em particular, não são transmitidos por herança e tem uma profunda vinculação ou com a região ou com um amplo contingente da população; a evidência de que a instituição não tem dono aparece, entre outras, na rotatividade dos cargos de direção da universidade; o controle e a participação no poder está com amplos segmentos da sociedade civil, através de suas organizações mais representativas.

O que as distingue das estatais e das particulares, conforme Gadotti (2005) não é tanto o seu estatuto jurídico, mas o seu projeto pedagógico, entendido num sentido mais amplo de projeto social e político. Portanto, o que constitui o seu perfil básico é o seu caráter público, social e realmente comunitário.

Longhi (1988) buscou aprofundar o estudo das universidades comunitárias, no sentido de caracterizar as diferenças, ao lado das semelhanças. Destacou também a existência de diferenças, a partir do gerenciamento, da estrutura do poder, da propriedade patrimonial, das fontes de recursos, do controle e da aprovação dos orçamentos e relatórios de gestão. No caso das universidades, de direito privado e confessionais, o termo parece indicar muito mais a característica de seus instituidores, como uma comunidade de pessoas, congregadas pela identidade na fé, na missão, pelos valores morais e religiosos e, em decorrência, organizados para oferecer serviços de educação à sociedade da qual fazem parte. No caso das universidades comunitárias, o sentido comunitário tem suas raízes em uma concepção de comunidade, cuja instituição ultrapassa a razão da universidade, que se aprofunda em outros sentidos e significados.

Pode-se dizer que as universidades comunitárias representam um esforço das comunidades em construírem seus espaços de ensino superior, uma vez que o Estado, independente das razões, não ofereceu o acesso ao ensino público estatal. 
Retomando a linha de pensamento sobre as Universidades comunitárias, Franco e Longhi $^{4}$ (2008) afirmam que as IES comunitárias são exemplos da diversificação do Sistema de Educação Superior construído a partir da Constituição Federal e da LDB, elas (IES comunitárias) tem sido estudadas sob duas ideias centrais: a procura de diferenciação em face dos demais segmentos da Educação Superior e o seu caráter alternativo. Neste contexto as instituições de educação superior comunitárias encontram-se inseridas em um marco diferencial das IES de orientação comercial, conforme Franco e Longhi destacam

\begin{abstract}
o caráter alternativo tem expressão no esforço de conferir ao segmento das IES comunitárias um traço diferenciador daquelas particulares de orientação comercial, e de entendê-las, mesmo que privadas, em uma perspectiva de instituições públicas não estatais (2008, p.186).
\end{abstract}

Até a metade dos anos 1960, segundo Bitar (2000), a educação superior brasileira era composta quase que exclusivamente por universidades públicas e confessionais que tinham como preocupação primeira difundir os princípios de suas crenças não se preocupando com a busca do lucro. Porém, ainda hoje, "não se pode negar que uma das grandes questões continua sendo o financiamento das universidades, especialmente no tocante as confessionais que, até início dos anos 70, ainda eram destinatárias de verbas governamentais” (p. 3).

Mesmo tendo sua origem no século passado, as UC tiveram o reconhecimento oficial somente em 2013, por meio da lei 12 881/2013, que dispõe sobre a definição, qualificação, prerrogativas e finalidades da Instituições Comunitárias de Educação Superior - ICES. A lei descreve características básicas para a qualificação das UC: constituição na forma de associação ou fundação de direito privado, patrimônio pertencente a sociedade civil ou ao poder público, não distribuição da sua renda, aplicação integral dos recursos nas suas atividades e desenvolvimento permanente de ações comunitárias.

As ICES contam com as seguintes prerrogativas: ter acesso aos editais de órgãos governamentais de fomento direcionado às instituições públicas e receber recursos orçamentários do poder público. Acredita-se que a legislação veio reconhecer o papel das instituições comunitárias e precisar a sua real identidade.

As IES Comunitárias foram criadas na década de 1940 e consolidadas na década de 1980, totalizando, em 2013, 63 IES agregadas a Associação Brasileira das Universidades Comunitárias (ABRUC) ${ }^{5}$. Para a Vanucchi (2003), a UC é uma universidade instituída,

\footnotetext{
${ }^{4}$ Citando estudos anteriores (Longhi, 1998; Bittar, 1999; Neves, 2003; Morosini e Franco, 2004).

5 A ABRUC fundada em 1995, tem como finalidades: promover o desenvolvimento e a integração das Instituições de Ensino Superior Comunitárias Brasileiras, fortalecendo a sua autonomia e buscando,
} 
mantida e supervisionada por uma pessoa jurídica de direito privado, sem fins lucrativos, gerida por colegiados constituídos de representantes dos professores, alunos e funcionários e da sua entidade mantenedora, bem como da sociedade em geral.

Esse modelo próprio de educação superior brasileira, baseado nas Universidades Comunitárias em sentido restrito, distingue-se das demais instituições de ensino superior privada em vários aspectos, segundo Schmidt e Campis, "a inexistência de fins lucrativos, a gestão democrática, a transparência administrativo-financeira, o controle social, a prestação de contas à sociedade e ao poder público e a ênfase no desenvolvimento regional”. (2009, p.29). Corrobora com estas características, as palavras de Morais "quanto à estritamente comunitárias o traço marcante seria sua vinculação à comunidade: é patrimônio de uma comunidade, administrativamente, subordina-se ao Conselho de representantes da comunidade". (1989,p.13). A educação comunitária explicita Gadotti (2005) procura mostrar a integração do local com o nacional e o transnacional. Fortalece esta ideia, Gutiérrez (2005) ao definir que a dimensão comunitária, vai além da dimensão individual e familiar e constitui uma contribuição substantiva e nova aos processos educativos inerentes ao desenvolvimento sócio-político. A dimensão comunitária extrapola a dimensão individual e familiar, alocando-se em outra esfera, na dimensão coletiva. $\mathrm{Na}$ medida em que as instituições comunitárias foram se constituindo, os movimentos de definição/consolidação do caráter comunitário se proliferaram. Neste sentido, algumas instâncias forma criadas, como a Associação Brasileira das Universidades Comunitárias - ABRUC, já citado anteriormente. É importante frisar que o estatuto da ABRUC, no artigo $7^{\circ}$ salienta que a mantenedora preencha cumulativamente alguns requisitos, entre eles: ter como instância máxima uma Assembleia ou Conselho com a participação de representantes da comunidade na qual está inserida; ter o controle da administração da gestão financeira de todos os seus recursos através de organismos com a participação da comunidade à qual está vinculada e no caso das fundações, também através do Ministério Público; manter sempre presente seu objetivo social, considerada a natureza e o interesse público de suas atividades.

O espaço de atuação das Universidades Comunitárias não estatais é o espaço de serviços não oferecidos pelo Estado. Segundo Schmidt e Campis (2009), as Universidades Comunitárias formam o maior sistema de educação superior do Rio Grande do Sul e de Santa Catarina e constituem um modelo próprio da educação superior brasileira. Surgem a partir da juízo ou fora dele, as Instituições membros, sempre que se tratar de assuntos de interesse comum. 
década de 1950, fruto da mobilização das comunidades regionais, decididas a suprir a carência de educação de nível superior em face da incapacidade do estado em prover tal serviço. Em pouco tempo, mostram-se capazes de cobrir as diversas regiões dos estados sulinos. No Rio Grande do Sul, as universidades comunitárias, organizam-se no Consórcio das Universidades Comunitárias Gaúchas - COMUNG, criado em 1996, com 15 universidades associadas. Em Santa Catarina, as universidades comunitárias organizam-se na Associação Catarinense das Fundações Educacionais - ACAFE, fundada em 1974 e que congrega 16 fundações educacionais, criadas com apoio do Governo do Estado e de Prefeituras. A ACAFE e o COMUNG expressam a organização das instituições comunitárias.

Ressalta-se que o processo de origem do modelo comunitário iniciou no final da década de trinta, mas incrementou-se a partir da década de cinquenta, no Rio Grande do Sul. Quanto às UC de Santa Catarina, o modelo incrementou-se a partir da década de 1960. Para uma melhor compreensão do panorama das UC no Rio Grande do Sul e em Santa Catarina, apresenta-se o quadro a seguir.

Tabela 1 - Universidades Comunitárias no RS e SC - funcionamento e reconhecimento ${ }^{6}$

\begin{tabular}{|c|c|c|}
\hline Décadas & Início de Funcionamento & $\begin{array}{c}\text { Reconhecimento como } \\
\text { Universidade }\end{array}$ \\
\hline 1930 & PUCRS & PUCRS \\
\hline 1940 & UNICRUZ & - \\
\hline 1950 & UCS, UCPel, UNIJUÍ, UPF, UNISINOS & - \\
\hline 1960 & $\begin{array}{c}\text { URI, URCAMP, UNISC, FEEVALE, UNISUL, UNIVALI, } \\
\text { UNESC, UNIPLAC, UNIVILLE, UNOESC, FURB }\end{array}$ & UCPel, UCS, UNISINOS, UPF \\
\hline 1970 & UNOCHAPECÓ, UnC & $\begin{array}{c}\text { UNIJUÍ, URCAMP, UNISUL, } \\
\text { UNIVALI, FURB, UnC }\end{array}$ \\
\hline 1980 & - & $\begin{array}{c}\text { UNICRUZ, UNISC, URI, } \\
\text { UNESC, UNIPLAC, } \\
\text { UNIVILLE, UNOESC }\end{array}$ \\
\hline 1990 & - & UNOCHAPECÓ \\
\hline 2000 & - & FEEVALE \\
\hline 2010 & - & \\
\hline
\end{tabular}

Fonte: elaborada com base em Bittar (2000)

\footnotetext{
6 As siglas representam PUCRS - Pontifícia Universidade Católica do Rio Grande do Sul; UCPel Universidade Católica de Pelotas; UCS - Universidade de Caxias do Sul; UPF - Universidade de Passo Fundo; UNISINOS - Universidade do Vale dos Sinos; UNIJUÍ - Universidade Regional do Noroeste do Estado do Rio Grande do Sul; URCAMP - Universidade da Região da Campanha; UNICRUZ - Universidade de Cruz Alta; UNISC - Universidade de Santa Cruz do Sul; URI - Universidade Regional Integrada do Alto Uruguai e das Missões; FEEVALE - Universidade Federação de Estabelecimento de Ensino Superior em Novo Hamburgo; UNISUL - Universidade do Sul de Santa Catarina; UNIVALI - Universidade do Vale do Itajaí; UNOCHAPECÓ - Universidade Comunitária da Região de Chapecó; UNESC - Universidade Comunitária de Criciúma; UNIPLAC - Universidade do Planalto Catarinense; UNIVILLE - Universidade da Região de Joinville; UNOESC - Universidade do Oeste de Santa Catarina, FURB - Universidade de Blumenau; UnC Universidade do Contestado.
} 
Percebe-se, no contexto da universidade brasileira, o modelo das instituições comunitárias, presente especialmente no Sul do Brasil, que apresenta, entre outras características, a gestão democrática e participativa.

\section{O DESENVOLVIMENTO REGIONAL NA UNIVERSIDADE DE PASSO FUNDO}

Dentre as universidades comunitárias que compõem o Comung, está a Universidade de Passo Fundo, que, em 2016, completou 48 anos de existência.

Os primórdios dessa instituição, na década de 1950, já sinalizavam para o cunho comunitário. A UPF, desde a origem, em 1968, adotou uma vocação regional: seu primeiro estatuto já definiu que um dos objetivos da Instituição consiste em contribuir para o desenvolvimento socioeconômico da região.

Nos movimentos sócio históricos dos primórdios da UPF, os elementos que se sobressaem na constituição dessa universidade comunitária caracterizam-se pelas lideranças e iniciativas de várias pessoas que não esperaram pacientemente pela iniciativa do Estado (o que de fato não ocorreu) e, partindo das necessidades locais, tomaram decisões para a implantação do ensino superior. É necessário salientar que esse contexto não foi linear e harmonioso, mas repleto de desafios, frustações, disputas, conflitos, avanços e retrocessos.

A UPF tem suas ações norteadas e sustentadas por quatro pilares: ensino, pesquisa, extensão e inovação tecnológica. Nessas quase cinco décadas, formou mais de 70 mil profissionais. Tem como missão: produzir e difundir conhecimentos que promovam a melhoria da qualidade de vida e formar cidadãos competentes, com postura crítica, ética e humanista, preparados para atuarem como agentes de transformação e como visão: consolidar-se como universidade comunitária regional, pública não estatal, de excelência, por meio do reconhecimento de sua qualidade, valores acadêmicos, seu compromisso social e suas ações inovadoras e sustentáveis. Entre seus valores está a gestão colegiada e planejada e o compromisso com o desenvolvimento regional.

Pode-se inferir pela fala dos gestores entrevistados, a relação entre universidade e comunidade.

Ela é comunitária desde sua origem por atender uma lacuna do Estado. Eu vejo que todo esforço da universidade dos processos de planejamento de desenvolvimento vem no sentido de fazer uma leitura dessa realidade e tentar por meio dos diferentes cursos, quer graduação, pósgraduação, as atividades, os projetos de extensão, de stricto sensu, lato sensu, responder 
minimamente a essas necessidades. É uma universidade que olha pra esse entorno, que na verdade ela é parte, não pode ser colocada fora desse contexto, ela procura fazer esse exercício de avaliar esse contexto e ver de que formas ela pode produzir e gerar conhecimentos com essa comunidade (G 8).

Eu acho que nós somos referências... quando nós pensamos no nosso programa, e pensamos quem são nossos alunos, temos muito egressos, tem alunos de São Borja, Chapecó, Xanxere, Joaçaba, Concórdia. Esse pólo de abrangência da UPF não é tão restrito quanto a gente pensa. Também tem um diálogo muito grande com questão do regional, a questão do olhar dela sobre comunidade. (G 2).

Para compreender melhor os movimentos da universidade, sua inserção e compromisso com o desenvolvimento regional, faz-se necessário compreender o conceito de região e desenvolvimento.

Etimologicamente, a palavra região, segundo o Dicionário Etimológico da Língua Portuguesa, vem do latim regionalis que significa grande extensão do terreno, território que se distingue dos demais por possuir características próprias. Dallabrida e Becker (2000) esclarecem que a região é uma especificação de uma totalidade (espaço), da qual faz parte através de uma articulação que é, ao mesmo tempo, funcional e espacial. Regionalizar seria, então, a tarefa de dividir o espaço segundo diferentes critérios que são devidamente explicitados e que variam segundo as intenções explicativas de cada conceito. É lugar das relações, relações sociedade natureza e homens-homens, em função disso, espaço de ação e de poder.

A respeito da questão da região, um gestor assim se manifesta:

Ela extrapola o que gente poderia chamar por uma região se pensar assim geograficamente. Nesse sentindo eu acredito que ela vai para além do regional até pelas proximidades com outro estado, com estado de Santa Catarina, como ela estende as suas ações, tanto para aluno de graduação com os da pós-graduação, lato sensu, stricto sensu no meu posicionamento, ela vai para além do regional. A questão do caráter comunitário além daquelas questões específicas do ponto de vista da organização de uma instituição comunitária, a característica da identidade comunitária, é por ela ter essa imersão aqui na comunidade, isso sim é um 'locus' bem pontual, ela tem inserção comunitária, ela tem referência comunitária, ela é escolhida, identificada na comunidade (G 6).

Ao fazer a distinção entre regionalismo de regional e universalismo de universal, Pozenato (2009) salienta que regionalismo e universalismo correspondem a uma programação, a uma decisão fundada em pressupostos ideológicos e em convenções estéticas. O regional se opõe ao nacional enquanto critério externo de demarcação de um corpus, é uma forma do particular.

A inserção regional fica expressa na seguinte colocação do gestor: 
A principal característica é o fato de não possuir um "dono" e a gestão democrática que predomina em todas as unidades e setores que a compõem. A destinação dos seus recursos exclusivamente para fins de ensino, pesquisa, extensão é outra características de sua natureza comunitária. A inserção regional pode ser identificada pela preocupação prioritária da instituição com os problemas e questões regionais, muito embora atrelados prioritariamente aos interesses dos grupos sociais mais privilegiados. No entanto, algumas unidades tem procurado voltar-se para os problemas que atingem outros grupos sociais na região, como os pequenos produtores, grupos de periferias urbanas, grupos indígenas e outros grupos socialmente marginalizados (G 3).

Já a palavra desenvolvimento sinaliza a ideia de crescimento econômico, social e político de um país, região, comunidade. Para melhor entendimento sobre o desenvolvimento local, Amaro (2009) faz uma retrospectiva histórica deste conceito.

Quadro 1 - Histórico do conceito de desenvolvimento local

\begin{tabular}{|c|l|}
\hline Data & \multicolumn{1}{|c|}{ Histórico } \\
\hline 1950 & $\begin{array}{l}\text { Definição de desenvolvimento e aplicação de ajuda aos novos países independentes (antigas colônias } \\
\text { européias), chamados de "subdesenvolvidos" que e afirmava-se que teriam muito a aprender com os países } \\
\text { "desenvolvidos" (antigas potências colonizadoras) }\end{array}$ \\
\hline 1970 & Afirmação científica do conceito \\
\hline 1980 & $\begin{array}{l}\text { Proposta do "Programa Iniciativas Locais de Emprego" da OCDE e sua importância na definição das } \\
\text { políticas européias de combate ao desemprego e à pobreza e exclusão social na União Européia }\end{array}$ \\
\hline 1990 & Reconhecimento político-institucional pelo PNUD* e pela OIT* \\
\hline
\end{tabular}

Fonte: elaborado com base em Amaro (2009)

Nota: PNUD - Programa das Nações Unidas para o Desenvolvimento e OIT- Organização Internacional do Trabalho.

Percebe-se que inicialmente, a questão do desenvolvimento estava atrelada a ajuda dos países desenvolvidos para com os novos países independentes, mas "subdesenvolvidos". $\mathrm{Na}$ década de 1980, o desenvolvimento estava vinculado a iniciativas locais de emprego, desencadeada pela OCDE. Esta vinculação assumiu importância na definição de políticas européias de combate ao desemprego. E mais recentemente, na década de 1990, o conceito de desenvolvimento local aparece em documentos do PNUD e da OIT. A partir do histórico do conceito de desenvolvimento local, Amaro sinaliza para a definição de desenvolvimento local como

o processo de satisfação de necessidades e de melhoria das condições de vida de uma comunidade local, a partir essencialmente das suas capacidades, assumindo a comunidade o protagonismo principal nesse processo e segundo uma perspectiva integrada dos problemas e das respostas. (...) corresponde sobretudo a uma multiplicidade assinalável de iniciativas de base local, a partir das quais, atores locais, de muitos tipos e numa variedade de situações, tentam encontrar repostas para os problemas colocados pelas crises econômicas, tecnológicas, ambientais e políticas (2009, p. 108).

Dando prosseguimento, Amaro (2009) afirma que as respostas locais devem vir ao encontro dos problemas econômicos (crises setoriais, falências e fechamento de empresas, 
desestruturação das economias locais), sociais (desemprego, pobreza e exclusão social, ausência de respostas sociais para o acompanhamento dos mais novos e dos mais velhos), culturais (marginalização ou descaracterização das identidades, dos valores culturais e dos patrimônios locais, homogeneização cultural) e ambientais (destruição dos ecossistemas locais, falta de saneamento básico, ameaças à qualidade de vida, extinção de espécies, deflorestação). E define o desenvolvimento local a partir de 10 atributos:

\begin{abstract}
Um processo de mudança, levando à melhoria do bem estar e das condições de vida da população; Centrado em uma comunidade territorial de pequena dimensão definida pela existência de uma identidade comum; Suas motivações são a resposta a necessidades básicas da comunidade; Mobilização das capacidades locais; Metodologias participativas e de "emporwerment" (delegação de poderes de decisão) da comunidade local ( do ponto de vista individual e coletivo); Contribuição de recursos exógenos, capazes de mobilizar e fertilizar os recursos endógenos ( e não de os substituir ou inibir); Perspectiva integrada na abordagem dos problemas e das respostas; Trabalho de parceria, articulação de vários atores, protagonistas e instituições locais; Impacto tendencial em toda a comunidade; Uma grande diversidade de processos, dinâmicas e resultados $(2009$, p. 111).
\end{abstract}

Nesta acepção de desenvolvimento, Amaro sinaliza para uma outra perspectiva metodológica de abordagem dos processos de desenvolvimento, a que designou de "Desenvolvimento Comunitário”, centrado na comunidade local e no seu território, com as consequências em termos teóricos e práticos daí resultantes.

Endossa estes atributos, Dallabrida e Becker (2000) ao conceituar Desenvolvimento Local/Regional que se refere a um determinado processo de territorialização que contempla a dimensão da reterritorialização, capaz de estimular as potencialidades e contribuir para a superação dos desafios locais/regionais, que privilegie a dimensão da inclusividade, capaz de eliminar privações ou não-liberdades, capaz de promover os atores/agentes regionais à condição de sujeitos, que envolva os territorializados, os que estão em processos de desterritorialização e os já desterritorializados, potencializando sua capacidade de autoorganização, implementando uma dinâmica territorial do desenvolvimento mais autônoma, não privatista, menos desigual.

Nessa perspectiva um gestor assinala:

O que torna ela mais comunitária é essa questão que estamos constante interação com a comunidade, principalmente pela vice-reitoria e extensão de assuntos comunitários, mas toda essa nova área inovação da tecnologia só tem sentido se a comunidade está por dentro que está acontecendo (G 7).

No contexto territorial, existe uma demanda de que as Instituições de Ensino Superior - IES, principalmente as universidades comunitárias, representem a principal mola propulsora 
do desenvolvimento nos âmbitos humano, social e econômico, na medida em que produzem conhecimento da/ com/ para a sua realidade. Na perspectiva das IES e do desenvolvimento em vários âmbitos é necessário a "inclusão do outro", dos que pertencem ao território, dos desterritorializados e dos reterritorializados, dos conhecidos e dos estranhos à comunidade.

Nesta perspectiva, os gestores assinalam:

Penso que a UPF tem caráter comunitário e regional. O primeiro elemento é a democracia interna, a tomada de decisões que envolve a comunidade, os órgãos colegiados. A segunda é o Plano de Desenvolvimento Institucional, o planejamento desta inserção regional a responsabilidade com Passo Fundo e o Planalto Médio. Outro elemento é a preocupação de dispor serviços à comunidade que o poder público não oferece. ( $\mathrm{G} 4)$.

Concebo sim a UPF como comunitária em função dos muitos programas das relações que ela tem com a comunidade local e regional tanto no âmbito das parcerias na área da educação, da saúde, nas áreas das ciências agrárias e isso tudo ajudou no desenvolvimento dessa região, no desenvolvimento regional, eu concebo inclusive aqui de abrangência de Passo Fundo, como uma região pobre e que ela foi puxada pela Universidade, o desenvolvimento dessa região ele é liderado pela Universidade. Isso é claramente visível na área da saúde, onde Passo Fundo é um pólo de pesquisa, de atendimento médico de excelência, de excelência médica que é referência em todo Brasil. (G 1).

Pode-se perceber que a inserção comunitária é ilustrada no depoimento a seguir:

vivemos no mundo hoje, chamamos de pós moderno, não existe mais uma identidade, mas existe identificações. Vivemos num mundo, extremamente fragmentado, precário, no sentido que não existe mais essa totalidade, então claro cada universidade, no nosso caso a UPF está buscando construir isso internamente, seja por lado da pesquisa, extensão, graduação, e enfim, nós estamos construindo esse nosso papel na região, muitas coisas deram certo, mas outras não estão tão certas assim, acho isso um processo, que uma universidade regional tem que constantemente construir, essa é a palavra chave construir, nós estamos buscando identidade a todo dia, estamos negociando com futuro, negociar com futuro significa não só ensinar coisas para nossos alunos, mas aprender coisas com nossos alunos.(G 5).

Nas palavras do gestor, "estamos construindo nosso papel na região". Corrobora Bobbio et al. (2007), ao salientar que o regionalismo apresenta a tendência política dos que são favoráveis às autonomias regionais. Nesse contexto, as universidades comunitárias, talvez mais do que as públicas e particulares, estão associadas à comunidade e ao desenvolvimento regional.

Mas de que desenvolvimento se fala? Amaro (2009) contribui com tal reflexão, afirmando que o desenvolvimento local está associado à melhoria das condições de vida de uma comunidade, e esta assume o protagonismo desse processo. Salienta as iniciativas de base local, a partir dos atores locais na busca de respostas aos problemas econômicos, tecnológicos, ambientais e políticos. Pensar o desenvolvimento local sob essa ótica pressupõe pertencimento, autonomia, mobilização e protagonismo. 


\section{ENCAMINHAMENTOS CONCLUSIVOS}

Pesquisar a universidade comunitária é pesquisar o espaço, os tempos (histórico, presente, projetivo), as necessidades e os desejos dos sujeitos históricos na construção coletiva de um modelo diferenciado no cenário da educação brasileira.

As UC pela sua própria concepção, também têm o compromisso de serem (re) pensadas, em um processo de ação-reflexão-ação, em todas as suas instâncias, ou seja, na graduação, pós-graduação, pesquisa, extensão e gestão. Esse modelo de universidade traz em seu bojo a dimensão pública da educação superior.

O sentido comunitário pressupõe a percepção do "nós" e, em consequência, o vínculo estabelecido de pertencimento, de compromisso, embora esse sentido de pertencimento não exclua as tensões existentes, os desafios. Nesse contexto, pensar o desenvolvimento regional é pensar o compromisso social da universidade comunitária.

Esse compromisso da UC abarca a contextualização da realidade na construção/produção do conhecimento que possibilita o desenvolvimento social e econômico na perspectiva da melhoria da qualidade de vida.

Nesse sentido, pelo estudo realizado, foi possível perceber, que muito além da missão, visão e valores, a UPF pela especificidade de sua trajetória institucional, percebe a comunidade como expressão da sua cultura, como fator fundamental para a busca de elementos significativos que permitam identificar os movimentos expressos em sua teia de significações que a constituem como a universidade comunitária.

Existe um encharcamento do caráter comunitário no cotidiano institucional, na gestão, e na construção do conhecimento e se expressa em pensar a comunidade, com a comunidade e para a comunidade, sentir-se parte dela, e, neste sentido, ser corresponsável pelo desenvolvimento regional.

\section{REFERÊNCIAS}

ACAFE. Disponivel em: https://www.acafe.org.br/new/index.php?endereco=conteudo Acesso em: 02 nov. 2016. 
AMARO, R. R. Desenvolvimento local. In: CATTANI, A. D. et al. (Orgs.). Dicionário internacional da outra economia. Coimbra: Almedina, 2009.

ARAUJO, M. M.; et all. A prática da indissociabilidade do ensino-pesquisa-extensão na universidade. Revista Brasileira de Agrociência. V. 4, n. 3, set./dez.,1998.

ASSOCIAÇÃO BRASILEIRA DAS UNIVERSIDADES COMUNITÁRIAS.Disponível em: <http://www.abruc.org.br/. Acesso em: 20 out. 2016.

BITTAR, Mariluce. O Ensino Superior Privado no Brasil e a Formação do Segmento das Universidades Comunitárias. (2000). Disponível em: www.anped.org.br/reunioes/23/textos/1108T.PDF. Acesso em: 20 nov. 2016.

BOBBIO, Norberto; MATTEUCI, Nicola; PASQUINO, Gianfranco. Dicionário de política. Brasília: Edunb, 2007.

BORDIGNON, L.B. A Pós-Graduação como Interlocutora das Relações Universidade e Comunidade. Tese de Doutorado em Educação da Universidade Federal do Rio Grande do Sul (UFRGS), Porto Alegre, 2014.

BRASIL. Constituições da República Federativa do Brasil. Disponível em: <http://www.planalto.gov.br/ccivil_03/constituicao/constituicao.htm>. Acesso em: 30 nov. 2016.

Lei de Diretrizes e Bases da Educação Nacional. Disponível em:

bd.camara.gov.br/bd/bitstream/handle/bdcamara/2762/ldb_5ed.pdf. Acesso em: 20 nov. 2016.

. Lei 12 881/2013. Disponivel em:<

http://legislacao.planalto.gov.br/legisla/legislacao.nsf/Viw_Identificacao/lei\%2012.8812013?OpenDocument>. Acesso em: 15 dez. 2013.

CHAUI, Marilena. Escritos sobre a Universidade. São Paulo: UNESP, 2001.

DALLABRIDA, Valdir Roque Dallabrida. BECKER, Dinizar Ferminiano. Governaça Territorial. Disponível em: https://revistas.unijui.edu.br/index.php/ desenvolvimentoemquestao/.../37. Acesso em: 20 jun. 2015.

FRANCO, Maria Estela; LONGHI, S. M.; RAMOS, M. G. Universidade e pesquisa: espaços de produção do conhecimento. Pelotas: Editora UFPel,, 2009

. LONGHI, Solange Maria. Universidades Comunitárias: forças e fragilidades. In: BITTAR, Mariluce et al. Educação Superior no Brasil - 10 anos pós LDB. Brasília: Instituto Nacional de Estudos e Pesquisas Educacionais Anísio Teixeira. 2008.

FRANTZ, W. Universidade Comunitária: uma iniciativa pública não estatal em construção. Unijui: Editora Unijui, 2004.

FREIRE, Paulo. Cartas à Cristina: reflexões sobre minha vida e minha práxis. São Paulo: Unesp, 2003. 
GADOTTI, Moacir.Educação Comunitária e Economia Popular. In: GADOTTI, Moacir; GUTIÉRREZ, Francisco (orgs). Educação Comunitária e Economia Popular. São Paulo: Cortez Editora, 2005.

GUTIERREZ, Francisco. Educação Popular e Desenvolvimento sócio-político. In:

GUTIÉRREZ, Francisco (orgs). Educação Comunitária e Economia Popular. São Paulo: Cortez Editora, 2005.

LONGHI, Solange Maria. A face comunitária da universidade. 1998. Tese (Doutorado em Educação) - Universidade Federal do Rio Grande do Sul, Porto Alegre, 1998.

MORAIS. João Luiz de (org). Perfil das Universidades Comunitárias. São Paulo: Loyola, 1989.

NEVES, Clarissa Eckert Baeta. Introdução. IN: FRANCO, Maria Estela Dal Pai (Org.).

Universidade, pesquisa e inovação. Passo Fundo: Ediupf; Porto Alegre: Edipucrs, 1997.

Desafios da Educação Superior. Dossiê Sociologias (2007).

Disponível em: http://www.scielo.br/pdf/soc/n17/a02n17.pdf. Acesso em: 24 out. 2011.

NÓVOA, Antonio. Catálogo da Universidade de Lisboa. Lisboa: Educa, 2011.

POZENATO, José Clemente. O Regional e o Universal na Literatura Gaúcha. Caxias do Sul: Educs, 2009.

READINGS, Bill. Universidade sem cultura. Rio de Janeiro: EduERJ, 2002.

SCHMIDT, João Pedro. CAMPIS. Luiz Augusto Costa a. As instituições comunitárias e o novo marco jurídico do público não estatal. In: SCHMIDT. João Pedro. (org). Instituições Comunitárias. Santa Cruz do Sul: EDUNISC, 2009

da ordem sociopolítica, 2011. Disponível em:

Comunidade e Comunitarismo: considerçãoes sobre a inovação <http://www.redalyc.org/pdf/938/93821299014.pdf>. Acesso em 02 mar. 2015.

SEVERINO, Antonio Joaquim. Pós-graduação, pesquisa e formação: desafios da contemporaneidade. In: Revista Espaço Pedagógico. Diposponível em:

<http://www.upf.br/seer/index.php/rep/issue/view/362/showToc>. Acesso em: 10 mar. 2015.

TRAMONTINI, Raulino; BRAGA, Ronald. As universidades comunitárias: um modelo alternativo. São Paulo: Loyola, 1988.

VANNUCCHI, Aldo. A Universidade Comunitária. São Paulo: Edições Loyola, 2004. 